\title{
Prevalence of Diabetes Mellitus Type 2 and its Association with Demography, Socio-Economy and Nutritional Status for Women of Amagoro Division in Western Kenya
}

\author{
Authors: Rebecca. A. Ebere ${ }^{1}$, Violet. N. Kimani ${ }^{2}$, Jasper. K. Imungi ${ }^{3}$ \\ ${ }^{I}$ Department of Food Science, Meru University of Science and Technology, Kenya \\ ${ }^{2}$ School of Public Health, University of Nairobi, Kenya \\ ${ }^{3}$ Department of Food Science, Nutrition and Technology, University of Nairobi
}

\begin{abstract}
Diabetes mellitus is rapidly increasing in Kenya. The prevalence varies among tribes and risk factors are not well understood. This study investigated the prevalence of diabetes mellitus in association with demography, socio-economy and nutritional status for women in Amagoro, Western Kenya. This was a descriptive cross-sectional study involving 260 women aged 15-90 years. Households were chosen by cluster and stratified sampling. Data on demography, socio-economy and diabetes status were collected by interviews using pre-tested questionnaires. Random blood sugar was measured using a glucometer and levels $\geq 7.8 \mathrm{mmol} / \mathrm{L}$ underwent confirmatory testing using fasting blood sugar. Anthropometric measurements were taken following standard protocols with some modifications. Body mass index as indicator of nutritional status was calculated by dividing weight $(\mathrm{kg})$ by height $\left(\mathrm{m}^{2}\right)$ and classified as underweight $(<18.5)$; normal weight (18.5-24.9); overweight (25.0-29.9) and obesity ( $\geq 30)$. Waist circumference $(W C)>88 \mathrm{~cm}$ and waist-hip-ratio $($ WHR $)>0.80$ were considered abnormal. Focus group discussions were conducted on participants' diabetes knowledge and selected repeated themes noted. Prevalence of diabetes was $16.9 \%$. Mean participants' age was $37.1 \pm 14.8$ years. Mean WC, BMI and WHR were 78.7 $\pm 9.9,22.7 \pm 3.44$ and $0.85 \pm 0.08$ respectively. Average income was KES 2438 \pm 2592 . Factors significantly associated with diabetes were employment status $(O R=3.16)$, income $(O R=14.21)$ and place of residence $(O R=4.54), p<0.05$.
\end{abstract}

Keywords: diabetes mellitus, demography, socio-economy, nutritional status, women from Western Kenya.

\section{Introduction}

Diabetes mellitus is a chronic medical condition whereby the blood sugar level of a person rises above normal [1]. The three main types of diabetes mellitus are type-1, type-2 (DM2) and gestational diabetes (GD) [1]. DM2 is the most common of diabetes representing about $85 \%$ of the cases worldwide [2]. In Sub-Saharan Africa, DM2 accounts for more than $90 \%$ of DM cases [3]. Causes attributed to DM2 are genetic and non genetic factors [1, 4]. It is more common in women, especially those with a history of GD [1] and those with a family history of diabetes [4]. Behavioural factors highly associated with DM2 include unhealthy diet, obesity and lack of physical activity [1]. These factors are strongly influenced by the demography and socio-economic status of the individuals which have been found to be associated with DM2 [5, 6, 7]. Some of the demographic and socio-economic risk factors include age, marital status and education and income levels. Also discussed is overweight/obesity as a risk factor for DM2.

The risk of DM2 increases with age [8] which could be due to weight gain, reduced physical activity $[9,10]$, the ageing pancreas and insulin resistance by cells [11]. Marital status has also been linked increased risk of DM2 especially widowed men possibly due to poor lifestyle [12]. There is conflicting evidence on the association between income levels and risk of DM2. Some study found the household income level to be inversely associated with DM2 [13] while another found the opposite and some found no association [14]. DM2 has been found to be inversely associated with level of education [7, 13, 15,]. Overweight/obesity especially aabdominal obesity has been associated with increased risk of DM2 [16] mainly because of associated insulin resistance [17]. Abdominal obesity is indicated by a waist-to-hip (WHR) ratio $>0.80$ for females [18] or a BMI $>30$ [19]. A waist circumference $>88 \mathrm{~cm}$ for women represent an increased diabetes risk [18, 19, 20].

In Kenya the prevalence of diabetes mellitus is rising and has been estimated at $2.7 \%$ in rural and $10.7 \%$ in urban areas (undated, DMI centre, Nairobi). A prevalence of $12 \%$ and $16 \%$ has been reported in urban and rural Kenya respectively [3,21]. Due to such inconsistency in the results, more prevalence studies need to be conducted. Also the risk factors could not be clearly established due to the limitations in the available data [3]. Nonetheless very little research has been done on diabetes mellitus type 2 in Kenya which has specifically targeted women as a group. The purpose of this study was therefore be to contribute to knowledge on the prevalence of diabetes among specialized groups of the population in the country and relate this to demography, socio-economy and nutritional status. 


\section{Materials and Methods}

The study was cross-sectional and it was conducted among women aged 15 - 90 years drawn from households located in Amagoro division of Western Province of Kenya. The study used a structured questionnaire to collect information through self-reporting. The interviews were conducted at the participants' home by trained research assistants. Focus group discussions were also conducted with participants drawn from those who took part in the survey.

Amagoro division is located in Teso North District of Busia County in Western Kenya. The participants were drawn from three locations selected from the nine locations. These were locations with many households, located to the north (Osajai), south (Kamolo) and central (Amagoro). The participants were then proportionately distributed among these locations depending on number of households in each location. The sample size was calculated according to the formula adopted from Fox and others [22] namely: N= P (100\%-P)/ $(\mathrm{SE})^{2}$. N= Desired sample size; $\mathrm{P}=$ Prevalence of diabetes in rural Kenya (Isiolo County) $(16 \%)$. SE= the confidence interval of $5 \%$ divided by 1.96 . In this case the $\mathrm{SE}=2.55$ and therefore $\mathrm{N}=207$. Allowing attrition, 260 households participated in the study.

This study was approved by Kenyatta National Hospital and University of Nairobi Ethics, Research and Standards Committee. Participants gave an informed consent and for those below 18 years, consent was sought from the guardian/parent. The inclusion criteria included being female, resides permanently in the household, sound vision, hearing and memory, understands the questions and agrees to participate. The exclusion criteria were poor vision, hearing and memory or being ill [17].

The outcome was diabetes mellitus which was diagnosed using random and fasting blood sugar levels. A random blood sugar (RBS) was obtained from a finger prick using a sterile lancet and glucose level was measured using a glucometer (Oncall Plus, U.S.A). Participants with a RBS $\geq 7.8 \mathrm{mmol} / \mathrm{l}$ were considered to have hyperglycemia and they underwent a confirmatory test the following morning using fasting blood sugar. Total diabetes was thus defined by those who reported to have been diagnosed with diabetes mellitus in addition to the newly diagnosed cases. A fasting blood sugar $\geq 7.0 \mathrm{mmol} / \mathrm{L}$ was considered as a confirmation for the disease [18]. Independent variables were demography, socio-economy and nutritional status. Age categorization was adopted from a previous study [20]. Education level and marital status were classified respectively into four (no formal schooling, primary education, secondary education and tertiary education) and four (single, married, divorced/separated, and widowed). Employment status, main source of household income and monthly household income were sorted respectively into four (unemployed, self employed, informal employment, formal employment), three (salary/wages, subsistence farming, small-scale business) and three (KES 0-4999, 5000$10000,10001-16000)$.

Nutritional status was assessed in terms of Body Mass Index (BMI). Height and weight were measured using standard protocols with a few modifications $[6,18]$. Height was measured using tape measure. Each subject was asked to remove any form of footwear and headgear. Height (in metres) was measured using a tape measure which was stuck to a flat wall, and the respondent was asked to stand on a flat surface. A wooden head rest was placed on the head, which allowed the measurement to be taken at the point perpendicular to the top of the head. With the feet together, heels against the wall and knees straight, the height was taken and recorded to the nearest $0.5 \mathrm{~cm}$. Weight was recorded using a bathroom scale (Camry Model: BR 9012, Germany), after calibrating to zero. The weighing scale was kept on a firm horizontal surface. Weight was recorded to the nearest $0.5 \mathrm{~kg}$. The subjects were asked to step onto the scale with the feet a stride, to stand still with the face forward and arms straight on the side. BMI was then computed and participants classified into underweight (BMI < 18.5); normal weight (BMI of 18.5-24.9); overweight (BMI of 25.0-29.9) and obesity (BMI $\geq 30$ ) [12]. Waist and hip circumference were also measured using standard protocols (WHO, 2011). Waist circumference > $88 \mathrm{~cm}$ and WHR $>0.80$ were considered to be abnormal [18]. Diabetes data and history of diabetes in the family were obtained from the self-reported questions. After the survey, some participants were invited to focus group discussions (FGDs). The discussions involved 7 to 10 members and a moderator and were conducted in local churches. A moderators' guide was used and findings were noted. A total of six FGDs were conducted.

The analyses were conducted using Statistical Package for the Social Sciences (SPSS) version 20.0. Descriptive statistics were used in analyzing and characterizing the sample. Data was presented in absolute frequencies, percentages, mean and standard deviation. A chi-square analysis was used to compare the outcome with independent variables. Binary logistic regression analyses were used to determine associations between DM2 and independent variables and multivariate logistic regression analysis to determine the magnitude of the independent risk factors. The significance level adopted in these tests was $5 \%(p<0.05)$. Findings from FGDs were summarized and repeated themes noted. 


\section{Results and Discussion}

All the participants were female, mainly from the Iteso community (91.2\%). Luhya's and other tribes were $6.5 \%$ and $2.3 \%$ of the participants respectively. Their mean age was $37.1 \pm 14.8$. The mean WC, BMI and WHR were $78.7 \pm 9.9,22.7 \pm 3.44$ and $0.85 \pm 0.08$ respectively. The participant's average income level was KES $2438 \pm 2592$ which mainly came from subsistence farming $(69.6 \%)$. These results are shown in TABLE I. DM2 has been associated with a number of risk factors including socio-demographic, socio-economic and nutritional factors.

\subsection{Socio-Demographic Characteristics of Respondents}

Majority of the women were young (15 - 34 years) and very few (3.1\%) were over 64 years. Most of them were married (90\%). Only $28.9 \%$ had received post primary education and $13.5 \%$ had never been school. Those with a family history of DM2 were $7.3 \%$. In addition, only $36(13.8 \%)$ lived in permanent housing while the rest lived on semi-permanent houses with only 7 (2.7\%) households connected to electricity. With regard to household size, 54.2\% comprised of 4-6 members while 1-3 member and 7-10 member households formed $16.2 \%$ and $29.6 \%$ respectively.

Table I: Distribution of participants with regard to socio-demographic characteristics

\begin{tabular}{|c|c|c|c|}
\hline \multirow[t]{2}{*}{ Variables } & \multirow[t]{2}{*}{ Categories } & \multicolumn{2}{|c|}{ Frequencies } \\
\hline & & $\mathrm{n}$ & $\%$ \\
\hline \multirow[t]{3}{*}{ Age (years) } & $15-34$ & 175 & 67.3 \\
\hline & $35-64$ & 77 & 29.6 \\
\hline & $\geq 65$ & 8 & 3.1 \\
\hline \multirow[t]{4}{*}{ Marital status } & Single & 16 & 6.2 \\
\hline & Married & 234 & 90 \\
\hline & Divorced/separated & 5 & 1.9 \\
\hline & Widowed & 5 & 1.9 \\
\hline \multirow[t]{4}{*}{ Level of education } & Never gone to school & 35 & 13.5 \\
\hline & Primary education & 176 & 67.7 \\
\hline & Secondary education & 46 & 17.7 \\
\hline & Tertiary education & 3 & 1.2 \\
\hline \multirow[t]{2}{*}{ Family history of diabetes } & Yes & 19 & 7.3 \\
\hline & No & 241 & 92.7 \\
\hline \multirow[t]{3}{*}{ Place of residence } & Kamolo & 97 & 37.3 \\
\hline & Amagoro & 98 & 37.7 \\
\hline & Osajai & 65 & 25 \\
\hline
\end{tabular}

Low level of education was found among the participants with very few progressing into higher levels of education. A majority had only gone to primary school. This is in agreement with an earlier study that found low enrolment of Kenyan women in post primary education [23]. As a result few women are in formal employment [23], a similar finding was found in this study. This low level of education may explain the relatively high prevalence of diabetes mellitus although this association was not significant. It's no wonder that women in the FGDs although aware of the rising cases of diabetes, they only associated diabetes to eating sugary foods and excessive body weight and were not aware of other predisposing factors.

\subsection{Socio-economic Characteristics of Respondents}

Most participants were unemployed and as a result nearly $70 \%$ relied on subsistence farming. Majority of the households' average monthly income was below KES 10,000. They all fall under Kenya's low income group [24]. However, this is a rural population that obtains most food through subsistence farming and therefore spend considerably less.

Table II: Distribution of participants according to socio-economic characteristics

\begin{tabular}{|l|l|c|c|}
\hline Variables & Categories & \multicolumn{2}{|c|}{ Frequencies } \\
\cline { 2 - 4 } & & \multicolumn{2}{|c|}{$\mathrm{n}$} \\
\hline Employment status & Unemployed & 135 & 51.9 \\
\hline & Self employed & 65 & 25 \\
\hline & Informal employment & 59 & 22.7 \\
\hline Main source of household income & Formal employment & 1 & 8.4 \\
\hline & Salary/wages & 23 & 6.8 \\
\hline & Farming (subsistence) & 181 & 69.6 \\
\hline
\end{tabular}


Prevalence of Diabetes Mellitus Type 2 and its Association with Demography, Socio-Economy and

\begin{tabular}{|l|l|c|c|}
\hline & Other & 13 & 5 \\
\hline Family monthly income (KES) & $0-4999$ & 222 & 85.4 \\
\hline & $5000-10000$ & 34 & 13.1 \\
\hline
\end{tabular}

\subsection{Nutritional Status of the Respondents}

The nutritional status was categorized in terms of BMI. In addition WC and WHR were used to define abdominal obesity and therefore the risk of DM2. The prevalence of overweight/obesity was $23.1 \%$. Those with abnormal WHR were $75.8 \%$. Majority of the participants $(82.7 \%$ ) had a normal WC (TABLE III).

Table III: Distribution of participants according to nutritional status

\begin{tabular}{|l|l|c|c|}
\hline Variables & Categories & \multicolumn{2}{|c|}{ Frequencies } \\
\cline { 3 - 4 } & & $\mathrm{n}$ & $\%$ \\
\hline Body mass index & Underweight & 18 & 6.9 \\
\hline & Normal weight & 182 & 70 \\
\hline & Overweight & 52 & 20 \\
\hline Waist circumference & Obesity & 8 & 3.1 \\
\hline & Normal & 215 & 82.7 \\
\hline Waist-to-hip ratio & Abdominal obesity & 45 & 17.3 \\
\hline & Normal & 63 & 24.2 \\
\hline
\end{tabular}

DM2 was then compared with the independent variables (TABLES IV-VI).

\subsection{Prevalence of Diabetes Mellitus}

The prevalence of DM2 among the women across all categories was found to be $16.9 \%$ (44 participants). Of this proportion (36) $13.8 \%$ were already diagnosed while (8) $3.1 \%$ were newly diagnosed cases. The newly diagnosed cases were $3.1 \%$ while the rest $(13.8 \%)$ were already diabetic. This figure is much higher than earlier reported in Kenya [3]. However, the prevalence in rural areas seems to be rising. Isiolo County, a rural population in Northern Kenya reported prevalence of $16 \%$ [21]. The rising prevalence could partly be due to increased awareness about the disease, improved diagnosis [25] and prevalence of human immunodeficiency virus (HIV)/AIDS [26] which was 6.4\% in women of western Kenya in 2007 [24]. HIV drugs have been associated with increased risk of DM2 [26] possibly due to associated obesity and cells developing insulin resistance [27]. The women who participated in the focus group discussions (FGDs) also agreed that the prevalence of diabetes is rising. They asserted that the disease can affect anyone and not as earlier believed that it only affects rich people and those with excessive body weight.

\subsection{Demography and Prevalence of Diabetes Mellitus}

Family history of diabetes and place of residence were significantly associated with diabetes mellitus-type 2 $(p<0.05)$. No association was found to exist between DM2 and age, marital status and level of education $(p>0.05)$ (TABLE IV).

Table IV: Distribution of the participants regarding diabetes by socio-demographic characteristics.

\begin{tabular}{|c|c|c|c|c|c|c|}
\hline \multirow[t]{2}{*}{ Variables } & \multirow[t]{2}{*}{ Categories } & \multicolumn{2}{|c|}{ Yes } & \multicolumn{2}{|c|}{ No } & \multirow[t]{2}{*}{$p$-value } \\
\hline & & $\mathrm{n}$ & $\%$ & $\mathrm{n}$ & $\%$ & \\
\hline \multirow[t]{2}{*}{ Age } & $<35$ & 20 & 45.45 & 116 & 53.7 & \multirow[t]{2}{*}{0.318} \\
\hline & $\geq 35$ & 24 & 54.55 & 100 & 46.3 & \\
\hline \multirow[t]{3}{*}{ Marital status } & Never married & 4 & 9.1 & 12 & 5.6 & \multirow[t]{3}{*}{0.529} \\
\hline & Married & 39 & 88.6 & 195 & 90.3 & \\
\hline & Divorced/separated/widowed & 1 & 2.3 & 9 & 4.2 & \\
\hline \multirow[t]{3}{*}{ Level of education } & Never been to school & 5 & 11.4 & 35 & 16.2 & \multirow[t]{3}{*}{0.188} \\
\hline & Primary education & 28 & 63.6 & 148 & 68.5 & \\
\hline & Secondary/Tertiary education & 11 & 25 & 35 & 16.2 & \\
\hline \multirow[t]{2}{*}{ Family history of diabetes } & Yes & 11 & 25 & 8 & 3.7 & \multirow[t]{2}{*}{0.000} \\
\hline & No & 33 & 75 & 208 & 96.3 & \\
\hline \multirow[t]{3}{*}{ Place of residence } & Kamolo & 22 & 50 & 75 & 34.7 & \\
\hline & Amagoro & 19 & 43.2 & 79 & 36.6 & 0.008 \\
\hline & Osajai & 3 & 6.8 & 62 & 28.7 & \\
\hline
\end{tabular}




\subsection{Socio-Economy and Prevalence of Diabetes Mellitus}

Employments status and family income were significantly associated with DM2 $(p<0.05)$. No association was found to exist between DM2 and income source $(p>0.05)$ (TABLE V).

Table V: Distribution of the participants regarding diabetes mellitus by socio-economic characteristics

\begin{tabular}{|c|c|c|c|c|c|c|}
\hline \multirow[t]{2}{*}{ Variables } & \multirow[t]{2}{*}{ Categories } & \multicolumn{2}{|c|}{ Yes } & \multicolumn{2}{|c|}{ No } & \multirow[t]{2}{*}{$p$-value } \\
\hline & & $\mathrm{n}$ & $\%$ & $\mathrm{n}$ & $\%$ & \\
\hline \multirow[t]{4}{*}{ Employment status } & Unemployed & 10 & 22.7 & 125 & 57.9 & \multirow[t]{3}{*}{0.000} \\
\hline & Self employed & 18 & 40.9 & 47 & 21.8 & \\
\hline & Informal/Formal employment & 16 & 36.4 & 44 & 20.4 & \\
\hline & & & & & & \multirow[t]{5}{*}{0.188} \\
\hline \multirow[t]{5}{*}{ Main source of household income } & Salary/wages & 7 & 15.9 & 16 & 7.4 & \\
\hline & Farming & 27 & 61.4 & 154 & 71.3 & \\
\hline & Business & 9 & 20.5 & 34 & 15.7 & \\
\hline & Other & 1 & 2.3 & 12 & 5.6 & \\
\hline & & & & & & \multirow[t]{4}{*}{0.000} \\
\hline \multirow[t]{3}{*}{ Family monthly income (KES) } & $0-5000$ & 31 & 70.5 & 201 & 93.1 & \\
\hline & $5001-10000$ & 10 & 22.7 & 14 & 6.5 & \\
\hline & $10001-16000$ & 3 & 6.8 & 1 & 0.5 & \\
\hline
\end{tabular}

\subsection{Nutritional Status and Diabetes Mellitus}

The prevalence of overweight/obesity was $23.1 \%$ with more than $75 \%$ having abnormal WHR. Despite this, there was no significant association between BMI, WHR and WC with DM2 ( $p>0.05)$ (TABLE VI). However those with abnormal WHR were 1.4 times more likely to have DM2 as opposed to those with normal WHR. This could possibly be due to the cut-off values used which may not be appropriate for this population. Despite these findings, other studies conducted in different parts of Kenya involving different communities had established a positive association especially between abdominal obesity and DM2 [21, 28]. Although they had low level of education, women in the FGDs were also aware of the link between excessive weight and a number of diseases including diabetes.

Table VI: Distribution of the participants regarding diabetes mellitus by nutritional status

\begin{tabular}{|c|c|c|c|c|c|c|}
\hline \multirow[t]{2}{*}{ Variables } & \multirow[t]{2}{*}{ Categories } & \multicolumn{2}{|c|}{ Yes } & \multicolumn{2}{|c|}{ No } & \multirow[t]{2}{*}{$p$-value } \\
\hline & & $\mathrm{n}$ & $\%$ & $\mathrm{n}$ & $\%$ & \\
\hline Body mass index & $<25$ & 34 & 77.3 & 166 & 76.9 & \multirow[t]{2}{*}{0.952} \\
\hline & $\geq 25$ & 10 & 22.7 & 50 & 23.1 & \\
\hline \multirow[t]{2}{*}{ Waist circumference } & $<88$ & 39 & 88.6 & 176 & 81.5 & \multirow[t]{2}{*}{0.253} \\
\hline & $\geq 88$ & 5 & 11.4 & 40 & 18.5 & \\
\hline \multirow[t]{2}{*}{ Waist-to-hip ratio } & $<0.8$ & 13 & 29.5 & 50 & 23.1 & \multirow[t]{2}{*}{0.367} \\
\hline & $\geq 0.8$ & 31 & 70.5 & 166 & 76.9 & \\
\hline
\end{tabular}

p-value: Pearson Chi-Square

Logistic regression analyses were conducted and results shown in Tables VII and VIII. With regard to age, the elderly ( $\geq 65$ years) were 1.2 times more likely to suffer from DM2 as compared to the young (15-34 years) although this finding was not statistically significant $(p>0.05)$. Also, those with abnormal WHR were about 1.4 times more likely to suffer from DM2 than those with normal WHR. Though not significant, those who never went beyond primary education or never went to school at all, have higher chances of suffering from DM2 as opposed to those with post primary education. These and other associations are shown in TABLE VII.

Table VII: Results of univariate logistic regression for diabetes mellitus

\begin{tabular}{|c|c|c|c|}
\hline Variables & Categories & $p$-value & OR $(95 \%$ CI-OR) * \\
\hline \multirow[t]{3}{*}{ Age (years) } & $15-34$ (ref) & - & 1.00 \\
\hline & $35-64$ & 0.491 & $0.79(0.40-1.56)$ \\
\hline & $\geq 65$ & 0.776 & $1.21(0.32-4.56)$ \\
\hline \multirow[t]{3}{*}{ Marital status } & Never married (ref) & - & 1.00 \\
\hline & Married & 0.321 & $1.83(0.55-6.07)$ \\
\hline & Divorced/Separated/Widowed & 0.699 & $1.30(0.35-4.91)$ \\
\hline \multirow[t]{3}{*}{ Level of Education } & Never gone to school & 0.351 & $1.74(0.54-5.54)$ \\
\hline & Primary education & 0.287 & $1.53(0.70-3.35)$ \\
\hline & Secondary/higher education (ref) & - & 1.00 \\
\hline \multirow[t]{2}{*}{ Employment status } & Unemployed & 0.001 & $4.55(1.92-10.76)$ \\
\hline & Self employed & 0.898 & $0.95(0.43-2.09)$ \\
\hline
\end{tabular}


Prevalence of Diabetes Mellitus Type 2 and its Association with Demography, Socio-Economy and

\begin{tabular}{|c|c|c|c|}
\hline & Informal/Formal employment (ref) & - & 1.00 \\
\hline \multirow{3}{*}{ Family monthly income (KES) } & $0-5000$ & 0.012 & $19.20(1.93-190.67)$ \\
\hline & 5001-10000 & 0.130 & $6.27(0.58-67.40)$ \\
\hline & $10001-16000$ (ref) & - & 1.00 \\
\hline \multirow{2}{*}{ Family history of diabetes } & Yes & 0.000 & $0.12(0.04-0.31)$ \\
\hline & No (ref) & - & 1.00 \\
\hline \multirow{2}{*}{ Body mass index } & $<25(\mathrm{ref})$ & - & 1.00 \\
\hline & $\geq 25$ & 0.952 & $1.02(0.47-2.22)$ \\
\hline \multirow{2}{*}{ Waist circumference } & $<88$ (ref) & - & 1.00 \\
\hline & $\geq 88$ & 0.258 & $1.77(0.66-4.78)$ \\
\hline \multirow{2}{*}{ Waist-to-hip ratio } & $<0.8$ (ref) & - & 1.00 \\
\hline & $\geq 0.8$ & 0.368 & $1.39(0.68-2.86)$ \\
\hline \multirow[t]{3}{*}{ Place of residence } & Kamolo & 0.570 & $0.82(0.79-3.49)$ \\
\hline & Osajai & 0.013 & $4.97(1.41-17.56)$ \\
\hline & Amagoro (ref) & - & 1.00 \\
\hline
\end{tabular}

Note: *OR (95\% CI-OR) means odds ratio and $95 \%$ confidence interval for the odds ratio.

The variables associated with DM2 $(p<0.05)$ from Table VII were employment status, family income and the place of residence. These variables were taken through multivariate logistic regression (TABLE VIII).

Table VIII: Results of multivariate logistic regression for diabetes mellitus

\begin{tabular}{|l|l|l|l|}
\hline Variables & Categories & $p$-value & OR (95\% CI-OR) $*$ \\
\hline Employment status & Unemployed & 0.02 & $3.16(1.22-8.19)$ \\
\cline { 2 - 4 } & Self employed & 0.19 & $0.55(0.22-1.34)$ \\
\cline { 2 - 4 } & Informal/formal employment (ref) & - & 1.00 \\
\hline \multirow{3}{*}{ Family monthly income (KES) } & $0-4999$ & & 0.04 \\
\cline { 2 - 4 } & $5000-10000$ & 0.15 & $6.0(0.51-84.61)$ \\
\cline { 2 - 4 } & $10001-16000$ (ref) & - & 1.00 \\
\hline \multirow{3}{*}{ Place of residence } & Kamolo & 0.03 & $4.54(1.17-17.55)$ \\
\cline { 2 - 4 } & Osajai & 0.19 & $0.58(0.26-1.30)$ \\
\cline { 2 - 4 } & Amagoro (ref) & - & 1.00 \\
\hline
\end{tabular}

Note: *OR (95\% CI-OR) means odds ratio and 95\% confidence interval for the odds ratio.

The results from the multivariate regression analysis above indicate that the variables most significantly associated with diabetes mellitus were employment status, family income and place of residence $(\mathrm{p}<0.05)$. Participants who are unemployed are thrice more likely to suffer from DM2 as opposed to those in formal employment while those earning less than KES 5000 per month also stand higher chance of being diabetic than those on a higher income bracket. A similar finding was reported in Northern Kenya where low economic status was found to increase the risk for DM2 [21]. Being unemployed and thereby having low income may predispose an individual to depression or stress which has been shown to increase diabetes risk [29] possibly because people under stress may not take good care of themselves; they develop unhealthy lifestyle behaviors such as poor dietary habits in terms of quality and quantity of food, low exercise levels, smoking and alcohol abuse [30, 31].

Residents of Kamolo were more than four times likely to suffer from diabetes mellitus as opposed to those residing in Amagoro while those in Osajai were less likely to suffer from the disease. These differences in risk could possibly be explained by the type of diet they subsist on as well as physical activities they could be engaged in and other possible environmental factors.

\section{Conclusions}

The prevalence of DM2 in Amagoro Division of Western Kenya is relatively high. This finding calls for regular screening of people for DM2 in Amagoro. Employment status, household income and place of residence were found to be the independent risk factors for DM2. Further study should be undertaken to establish the factors responsible for the high prevalence of DM2 in the region and especially in Kamolo area. Also, women in this region need to be empowered through improved access to education and employment so that they may boost their income levels and improve on their health.

\section{Acknowledgements}

The authors wish to thank the medical staff in Kocholia sub-county hospital for their assistance during data collection and Meru University of Science and Technology for financial support. 


\section{References}

[1] ADA (American Diabetes Association). Diagnosis and classification of diabetes mellitus. Diabetes Care 33(1), 2010, S62-69.

[2] WHO/IDF, Definition, diagnosis of diabetes mellitus and intermediate glycemic. Geneva: World Health Organization; WHO Report on diabetes and chronic non communicable diseases, www.who.int/diabetes/.../Definition\%20and\%20diagnosis\%20of\%20diabetes_new.pdf.

[3] S. Dalal, J.J. Beunza, J. Volmink, C. Adebamowo, F. Bajunirwe, M. Njelekela, D. Mozaffarian, W. Fawzi, W. Willet, H. Adami and M.D. Holmes, M.D, Non-communicable diseases in sub-Saharan Africa: what we know now, International Journal of Epidemiology, 40, 2011, 885-901.

[4] C. Herder and M. Roden, "Genetics of type 2 diabetes: pathophysiologic and clinical relevance", European Journal of Clinical Investigation, 41, 2011, 679-692.

[5] D.J. Corsi and S.V. Subramanian, Association between socioeconomic status and self-reported diabetes in India: a cross-sectional multilevel analysis. BMJ Open, 2012, doi:10.1136/bmjopen-2012-000895.

[6] C. Rao, V. Kamath, A. Shetty and A. Kamath, A study on the prevalence of type 2 diabetes in coastal Karnataka, International Journal of Diabetes Dev Ctries 30, 2010, 80-85.

[7] G. Veghari, M. Sedaghat, H. Joshaghani, S. Hoseini, F. Niknezad, A. Angizeh, E. Tazik, P. Moharloei, P, Association between socio-demographic factors and diabetes mellitus in the north of Iran: A population-based study, International Journal of Diabetes Mellitus 2, 2010, 154-157.

[8] S. Colberg, R. Sigal, B. Fernhall, J. Regensteiner, B. Blissmer, R. Rubin, L. Chasan-Taber, A. Albright and B. Braun, Exercise and Type 2 Diabetes, Diabetes Care 33, 2010, e147-e167.

[9] A. Donato, K. Tench, D. Glueck, D. Seals, I. Eskurza and H.Tanaka, Declines in physiological functional capacity with age: a longitudinal study in peak swimming performance, Journal of Applied Physiology, 94, 2003, 764-769.

[10] H. Tanaka and D.R. Seals, Endurance exercise performance in Masters Athletes: age-associated changes and underlying physiological mechanisms, The Journal of Physiology 586, 2008, 55-63.

[11] F. Booth, M. Laye and M. Roberts, Lifetime sedentary living accelerates some aspects of secondary aging, Journal of Applied Physiology, 111, 2011, 1497-1504.

[12] M.C. Cornelis, S.E. Chiuve, M.M. Glymour, S. Chang, E.J.T. Tchetgen, L. Liang, K.C Koenen, E.B. Rimm, I. Kawachi and L.D. Kubzansky, Bachelors, Divorcees, and Widowers: Does Marriage Protect Men from Type 2 Diabetes? PLoS ONE 9(9), 2014, doi:10.1371/journal.pone.0106720.

[13] J. Hwang and C. Shon, Relationship between socioeconomic status and type 2 diabetes: results from Korea National Health and Nutrition Examination Survey (KNHANES) 2010-2012, BMJ Open, 2014, 4:e005710 pmid: 25138810.

[14] T. Tanaka, E. Gjonca and M.C. Gulliford, M.C, Income, wealth and risk of diabetes among older adults: cohort study using the English longitudinal study of ageing, European Journal of Public Health 22, 2012, 310-317.

[15] J.C Lessmann, D.M.G.V Silva and S.M. Nassar, Women with type 2 diabetes mellitus: socio-demographic profile, biometrics and health, Acta Paulista Enfermagem, 25, 2012, 81-86.

[16] M. Moretto, M. Tadono, A. Neri, M. Guariento, Associations among self-reported diabetes, nutritional status, and sociodemographic variables in community-dwelling older adults, Revista de Nutricao Campinas 27, 2015, 653-664.

[17] A. Hussain, M.Z.I. Hydrie, B. Claussen and S. Asghar, Type 2 Diabetes and obesity: A review, Journal of Diabetology 2, $2010,1-7$.

[18] Ayah, M. Joshi, R. Wanjiru, E. Njayu, C. Otieno, E. Njeru and K. Mutai, A population-based survey of prevalence of diabetes and correlates in an urban slum community in Nairobi, Kenya, Biomed Central Public Health, 2013, doi: 10.1186/1471-2458-13-371.

[19] WHO (World Health Organization), Waist Circumference and Waist-Hip Ratio: Report of a WHO Expert Consultation Geneva, 811 December 2008, World Health Organization, 2011, http://apps.who.int/iris/bitstream/10665/44583/1/9789241501491 eng.pdf

[20] I. Gezawa, F. Puepet, B. Mubi, A.Uloko, B. Bakki, M. Talle and I. Haliru, I, Socio-demographic and Anthropometric risk factors for Type 2 diabetes in Maiduguri, North-Eastern Nigeria, Sahel Medical Journal, 18, 2015, S1-7.

[21] H. El-busaidy, M. Dawood, A. Kasay, C. Mwamlole, N. Koraya and H. Parpia, How Serious is the Impact of Type II Diabetes in Rural Kenya? The Open Diabetes Journal 7, 2014, 1-4.

[22] N. Fox, A. Hunn, A and N. Mathers, N, Sampling and sample size calculation. Leeds: The National Institute for Health ResearchResearch Design Service for the East Midlands / Yorkshire \& the Humber, 2009, http://www.webpages.uidaho.edu/ed571/571Modules/M3/NIHS-Sampling_Sample_Size_calculation.pdf.

[23] E. Onsomu, Profile of Women's Socio- Economic Status in Kenya. Institute of Economic Affairs, 2008, ISBN: 9966-7183-3-8.

[24] KNBS (Kenya National Bureau of Statictics), Economic survey, 2015, www.knbs.or.ke/index.php?...economic-survey2015...economic-survey.

[25] IDF (International Diabetes Federation, Atlas) In 5th edition, 2011, www.idf.org/diabetesatlas

[26] B. Ledergerber, H. Furrer, M. Rickenbach, R. Lehmann, L. Elzi, B. Hirschel, M. Cavassini, E. Bernasconi, P. Schmid, M. Egger and R. Weber, Factors Associated with the Incidence of Type 2 Diabetes Mellitus in HIV-Infected Participants in the Swiss HIV Cohort Study, Clinical Infectious Diseases 45, 2007, $111-119$.

[27] V. Hall, R.W. Thomsen, O. Henriksen and N. Lohse, Diabetes in Sub Saharan Africa 1999-2011: epidemiology and public health implications A systematic review, Bio Med Central Public Health, 11, 564, 2011, doi:10.1186/1471-2458-11-564.

[28] M.P. Chege, Risk factors for type 2 diabetes mellitus among patients attending a rural Kenyan hospital. African, Journal of Primary Health Care Family Medicine, 2(1), 2010, Doi: 10.4102/phcfm.v2i1.96.

[29] F. Pouwer, N. Kupper and M.C. Adriaanse, Does emotional stress cause type 2 diabetes mellitus? A review from the European depression in diabetes (EDID) research consortium, Discovery Medicine 9, 2010, 112-118.

[30] F. Bonnet, K. Irving, J.L.Terra, P. Nony, F. Berthezene and P. Moulin, Anxiety and depression are associated with unhealthy lifestyle in patients at risk of cardiovascular disease, Atherosclerosis, 178, 2005, 339-344.

[31] N.H. Rod, M. Grønbaek, P. Schnohr, E. Prescott and T. Kristensen, Perceived stress as a risk factor for changes in health behaviour and cardiac risk profile: a longitudinal study, Journal of Internal Medicine 266, 2009, 467-475. 